IZA DP No. 4491

Impact of Educational and Religious Homogamy on Marital Stability

Kornelius Kraft

Stefanie Neimann

October 2009 


\title{
Impact of Educational and Religious Homogamy on Marital Stability
}

\author{
Kornelius Kraft \\ TU Dortmund, \\ ZEW and IZA
}

Stefanie Neimann

TU Dortmund

and RGS Econ

\section{Discussion Paper No. 4491 \\ October 2009}

\author{
IZA \\ P.O. Box 7240 \\ 53072 Bonn \\ Germany \\ Phone: +49-228-3894-0 \\ Fax: +49-228-3894-180 \\ E-mail: iza@iza.org
}

Any opinions expressed here are those of the author(s) and not those of IZA. Research published in this series may include views on policy, but the institute itself takes no institutional policy positions.

The Institute for the Study of Labor (IZA) in Bonn is a local and virtual international research center and a place of communication between science, politics and business. IZA is an independent nonprofit organization supported by Deutsche Post Foundation. The center is associated with the University of Bonn and offers a stimulating research environment through its international network, workshops and conferences, data service, project support, research visits and doctoral program. IZA engages in (i) original and internationally competitive research in all fields of labor economics, (ii) development of policy concepts, and (iii) dissemination of research results and concepts to the interested public.

IZA Discussion Papers often represent preliminary work and are circulated to encourage discussion. Citation of such a paper should account for its provisional character. A revised version may be available directly from the author. 
IZA Discussion Paper No. 4491

October 2009

\section{ABSTRACT \\ Impact of Educational and Religious Homogamy on Marital Stability*}

Using a rich panel data set from the German Socio-Economic Panel, we test whether spouses who are similar to each other in certain respects have a lower probability of divorce than dissimilar spouses. We focus on the effect of homogamy with respect to education and church attendance. Gary Becker's theory of marriage predicts that usually, positive assortative mating is optimal. Our results, however, suggest that homogamy per se does not increase marital stability but higher education and religiousness.

JEL Classification: $\quad 120, \mathrm{~J} 12$

Keywords: divorce, homogamy, education

Corresponding author:

Kornelius Kraft

TU Dortmund

Volkswirtschaftslehre (Wirtschaftspolitik)

44221 Dortmund

Germany

E-mail: kornelius.kraft@tu-dortmund.de

* The authors thank participants of the Brown Bag Seminar in Dortmund and the RGS conference for helpful comments. Stefanie Neimann thanks Ruhr Graduate School in Economics for financial support. 


\section{Introduction}

For most developed countries, the last 40 to 50 years were characterized by dramatic changes in common family structures. Cohabitation, for example, is no longer a lifestyle disapproved of by many people but rather common among couples before marriage. Another remarkable phenomenon is the huge increase in divorce rates. In West Germany, the number of divorces per 10,000 marriages rose from 35.7 in 1960 to 118.4 in 2004 (Statistisches Bundesamt (2005)). However, divorce is usually a quite painful and far-reaching experience in life for all persons involved. It is a decision of serious consequences. Given the steady increase in the last decades, many researchers from different fields like genetics or psychology as well as economics have tried to shed light on the determinants of this decision. Other studies focus on the financial and non-financial consequences, in particular for women and children.

The present paper refers to one strand of the economic literature that tries to find out what factors make an optimal match of husband and wife. That is, what personal characteristics and what combinations of them have a stabilizing effect on marriage and what not? Do marriages between individuals who are similar to each other generally have a lower divorce probability? Our analysis concentrates on the effect of individual education and church attendance as well as spousal combinations of them. However, we also control for a large set of factors that have been proved to be important in the analysis of marital stability.

Education is a result of a number of factors that in turn also potentially affect marital stability, e.g. socialization or the attitude towards the traditional labor division within the household. On the other hand, education has an impact on other determinants of divorce like age at marriage, labor supply, or income. Hence, education may influence marital stability in many ways. Traditionally, husbands have a better education than their wives. Does this combination, however, promise a lower risk of disruption or are "modern" relationships with two equally educated spouses more stable? What happens if the wife is better educated than the husband? The consideration of educational combinations in our empirical analysis offers the opportunity to test the effect of similar versus different educational levels on the probability 
of divorce while we control for various other factors related to education as well as risk of disruption.

The stability of a relation is partly determined by the general attitude of the spouse towards marriage which is likely be affected by religiousness. Individuals that attend church services have probably a more traditional view on marriage and family and are therefore less prone to divorce than nonreligious people. The question is, however, what effect dissimilar preferences in this respect have. Do couples of two non-religious spouses have a lower risk of separation than couples with only one spouse interested in church because of their homogenous preferences in this respect?

Gary Becker's seminal model of household decision-making predicts that negative assortative mating (that is, mating of unlikes) is optimal concerning wage earnings capacity because it increases gains from specialization in market and housework, respectively. For all other factors, homogamy should have a stabilizing impact on marriage. Therefore, similar attitudes towards religion should decrease the probability of divorce. The impact of educational homogamy, however, is not clear: On the one hand, education has a huge impact on the individual's wage earnings capacity so that homogamy increases divorce probability. On the other hand, education contains a social or cultural element. In this respect, similarity should have a stabilizing effect (Becker (1973, 1974a); Becker et al. (1977)).

As alternatives to the Becker approach, bargaining models have been proposed (e.g. Manser and Brown (1980); McElroy and Horney (1981)). Usually, the division of household goods is not symmetric but depends on the two spouses' outside options. The latter are in turn largely affected by the educational level and labor supply.

Our questions of interest have been largely neglected by the economic literature but have been discussed more intensively by sociologists. Nevertheless, their results are rather mixed. For example, Koch (1993) cannot find any statistically significant effect of the difference in education on marital stability of West German couples. In contrast, Müller (2003) shows a higher probability of divorce if the husband is better educated compared to educational homogamous couples. 
For our analysis, complementary log-log (cloglog) and random effects-cloglog regression models are estimated with data from the German Socio-Economic Panel (SOEP), waves 1984-2007. The sample consists of West German couples only that are observed from the beginning of their marriage on until separation or right-censoring. The analysis focus on the effects of education and church attendance, nevertheless, various other factors are also controlled for like age at marriage, presence of children, or hours worked. Concerning education, it is not only distinguished whether both have the same degree or one spouse is higher educated but it is differentiated between different levels. In contrast to the few other existing German studies, information about church attendance is available for both spouses. In either case, we consider changes in the explanatory variables over the course of marriage and do not restrict our analysis to the situation at the beginning of marriage.

Our results do not generally confirm the stabilizing effect of homogamy. Apparently, positive assortative mating with respect to education does not enhance the stability of marriage despite of controlling for hours worked and unemployment experience. It rather depends on whether one or both spouses are only low-educated since these couples have a higher risk of divorce. As expected, people that attend religious events have a lower divorce probability. The stabilizing effect is even stronger if spousal combinations are considered. Couples with two spouses participating in religious activities are significantly more stable than any other combination. However, again homogamy per se does not lower the risk of divorce.

The paper is structured as follows. Section 2 contains a discussion about the effects of education and religious affiliation on marital stability in the context of the two most important theoretical frameworks. Section 3 reviews the relevant empirical literature, whereas section 4 describes the empirical approach and the data used. In section 5, empirical results are presented. Conclusions are given in section 6 . 


\section{Theoretical discussion on the effects of educa- tion and religious affiliation}

There are two classes of theoretical frameworks modeling the decision-making of a family. So-called unitary models or traditional household models assume a joint utility function for all household members, whereas the second class is based upon bargaining theory.

In the following, the two types are shortly presented in the context of marital stability. Focus is on the models' predictions concerning the relationship between the risk of divorce on the one hand, and education and religiousness on the other hand. Nevertheless, other factors are also discussed since they are influenced by education, e.g. labor supply or age at marriage.

\subsection{Unitary models}

Gary Becker is one of the most important contributors to the advancement of family economics. With his "Theory of Marriage" and later extensions (Becker (1973, 1974a); Becker et al. (1977)), he provided a framework that is still the basis for many analyses concerning the behavior of families.

The main implication of his model is that the family acts as if it were maximizing a joint utility function that incorporates the preferences of all family members. Utility depends on household goods like children, love, and affection. They are produced within the household with market goods, time of household members, and environmental variables (e.g. household's human capital) as input factors. The model implies that two persons marry when the expected utility from being married exceeds the expected utility from remaining single. Analogously, married couples separate when the expected utility from remaining married falls below the expected utility from divorcing and possibly remarrying. One reason for this turnover in expected utilities can be an unpredictable change in personal traits of the spouse that may cause the partner to reconsider his or her marriage decision. Thus, in such a stochastic framework, the probability of divorce depends on the expected gains from marriage and the distribution of unanticipated gains/losses from marriage. One objective of the model is to find characteristics and spousal combinations that minimize this probability of divorce by influencing the 
gains from marriage and their uncertainty.

In the Beckerian world, the gains from marriage do not only rely on economies of scale by joining households. The main factor is the complementarity of a man and a woman in the home production of household goods. Thus, these gains rise with increasing complementarity of inputs, namely market goods and time. This implies that the one with the higher wage earnings capacity should specialize in market work so that the household can afford more market goods. The other one should use his or her time for home production. This specialization gain is larger the higher the wage difference between the two spouses. Moreover, specialization implies a mutual dependence between the two mates. According to Becker, this aspect is the major incentive for partners to marry and, in the periods following, to stay together. Thus, every factor that makes the division of labor between husband and wife less advantageous decreases the mutual dependence and therefore raises the risk of marital disruption. Hence, negative assortative mating concerning wage earnings capacity (or other factors that are close substitutes) is optimal.

In principle, Becker's theory is gender-neutral. However, the economic provider role is traditionally assigned to husbands and the homemaker role to wives, to a certain degree due to their human capital investments before marriage. Consequently, the increase in educational attainment and labor market activity of women can be partially responsible for the rise in divorce rates in the last decades. By growing equalization of men and women, the incentives to marry and if married to stay together are reduced. ${ }^{1}$

Becker also provides an extensive analysis of optimal sorting with respect to other factors. He finds that positive assortative mating, i.e. mating of likes, is optimal for all other characteristics that are no good substitutes for the wage earnings capacity. Hence, homogamy with respect to interests, religiousness, age, etc. should stabilize a partnership. He further shows that, given positive assortative mating is optimal, gains from marriage are higher for persons with higher values of characteristics.

In our opinion, religious affiliation is a good candidate to get information about the impact of harmony in preferences. On the one hand, it stands

\footnotetext{
${ }^{1}$ There is also evidence, however, that educational institutions are very efficient marriage markets that lower search costs. See e.g. Lewis and Oppenheimer (2000) or Nielsen and Svarer (2006).
} 
for a traditional attitude towards the institution marriage. Religious people also usually live in an environment with religious peers that may stigmatize divorced couples more than unreligious persons. On the other hand, probably even more important than the individual attitude is the conformity of the spouses' preferences in this respect. It is very likely that individuals prefer a spouse who is of the same opinion concerning the importance of religion and hence, of marriage. Their relationships should therefore be more stable than between spouses with different views.

The impact of education is not that straightforward: On the one hand, education determines wage earnings capacity so that homogamy makes specialization less advantageous and therefore destabilize a marriage. On the other hand, education is part of the general process of socialization and may represent individual's preferences for the way of living. In this respect, similarity has a stabilizing effect that would further increase with higher education. The impact of the individual level is not obvious either: A good education improves the opportunities on the labor market which in turn makes an individual more independent from the partner. Hence, high education can destabilize a relationship. However, individuals with higher education are supposed to be more intelligent than others. This might imply that they are better able to form expectations about their spouse and his or her future characteristics. Therefore, they are less likely to become disappointed. An alternative interpretation is that they are better able to find a partner who is suited for lifetime. Both explanations would imply an inverse relationship between education and risk of divorce. In summary, the effects of education and its spousal combinations on marital stability are ambiguous. Moreover, the aspect of preferences concerning the educational level of the spouse is less clear than in the case of religiousness. Some may still prefer the traditional labor division and therefore look for a partner with a different education than the own one. Others may search for an equal spouse. Hence, the effect of education on marital stability via preferences is a priori also not clear.

Another uncertainty-reducing factor is the search duration on the marriage market. A longer or more intensive search should enhance the match quality because an individual gathers more information about potential mates and own preferences concerning the optimal partner. In empirical estimations, 
this factor is usually captured by age at the time of marriage. A higher age at marriage should stabilize a relationship because it usually implies a longer search history. However, he effect may not be continuously negative. There might exist an age threshold from which on a person accepts a match of lower quality in order to save further search costs. As a consequence, chance of divorce would be higher. However, we did not find evidence for a non-linear relationship in our data.

Nevertheless, there is no way to fully eliminate uncertainty. A typical example for unmet expectations is unemployment. It can be interpreted as a negative shock for each employed person that cannot only lower household's income but also self-esteem and self-confidence. These consequences affect marital stability negatively if gains from marriage are substantially reduced for at least one partner. As other labor force behavior variables, the risk of unemployment is also affected by education. Higher educated individuals have a lower probability of losing the job than others.

The Becker model considers children as marital-specific investments that stabilize a relationship. These "commodities" increase the gains from marriage since they make divorce more costly and thus, lower the probability that it occurs. Children from previous relationships, however, are usually not subsumed under marital-specific investments.

Some of the main assumptions of the unitary framework are subject of criticism. For example, it is not explicitly modeled in which way the individual preferences are incorporated in the joint utility function. Becker (1974b, 1981) suggests that it represents the utility function of the altruistic head of the family. In this case, neglecting other family members, the marital good is divided equally between the two spouses. Alternatively, one interprets the family utility function as the consensus between the members. On the whole, each interpretation is quite restrictive. Moreover, pooling of income is difficult to justify if each family member has different outside options. The validity of the unitary model can be tested by estimating whether the distribution of income among household members has a significant effect on demands for private goods. The model predicts insignificance. Several studies have found, however, that the distribution does matter and hence, reject the unitary model (e.g. Browning et al. (1994) or Hoddinott and Haddad (1995)). Furthermore, in times of increasing education and labor force par- 
ticipation rates of married women it is questionable that specialization still (if ever) constitutes the most important part of the gains from marriage. Nevertheless, despite their limitations, unitary models are still often used due to their simplicity and less stringent data requirements.

\subsection{Models with household bargaining}

The second class of models based on bargaining theory allow explicitly for conflicts of interest and provide a mechanism by which family behavior is formed from individual preferences. It is distinguished between cooperative and non-cooperative bargaining solutions. Most popular is, however, the cooperative Nash-bargaining model which we present in the following. Some authors have questioned cooperative and have favored non-cooperative models. However, in our opinion, if marriage is not suited for a cooperative solution, then the Nash-bargaining solution may not be used for any situation. Members of a family should be able to make binding agreements. Nevertheless, Binmore et al. (1986) derive the Nash-bargaining solution as the approximation of a non-cooperative game and show that this solution has a quite general theoretical foundation.

As a solution to distributional problems between two players, 1 and 2, Nash (1950) presented the allocation of goods $\left(x_{1}, x_{2}\right)$ that maximizes the product of the two persons' utility gains over the outcome in case of disagreement $\left(s_{1}, s_{2}\right)$ :

$$
\max _{x_{1}, x_{2}}\left(x_{1}-s_{1}\right)\left(x_{2}-s_{2}\right)
$$

subject to

$$
x_{1}+x_{2}=X \text {. }
$$

$X$ stands for the output of a marital production process defined as the output of home produced commodities (e.g. cooking, washing, child care) and consumption goods. In principle, both could be measured in monetary terms but often the home produced goods are not. The outcome in case of disagreement $\left(s_{i}\right)$ is also called threat point. The definition of it is problematic 
and at the same time crucial for the outcome of these models. In their models about household decision-making in a bargaining framework, Manser and Brown (1980) and McElroy and Horney (1981) define the individual situation in case of divorce as the threat point. Even though the credibility of a divorce-threat is questionable in day-to-day decisions its use in our analysis of divorce probabilities should be appropriate. ${ }^{2}$ Non-marketable goods like trust and mutual support are not included in $X$ even though they are very important factors for a successful partnership. ${ }^{3}$ It can be assumed that they either do not require time as input but other resources or that the time invested in the production of these particular goods is not associated with disutility like working in the labor market. Nevertheless, if these goods are absent, living together with a partner could create a public bad instead of a public good. In these cases, a spouse makes forecasts about the permanence of this situation and evaluates the utility derived from monetary as well as non-monetary factors. Only if there does not exist a monetary compensation high enough for the unhappy situation marriage ends in divorce. Therefore, we restrict our analysis to monetary factors but keep in mind the existence of non-monetary causes of divorce.

Solving the above optimization problem with respect to $x_{1}$ and $x_{2}$ yields:

$$
x_{1}=\frac{1}{2} X+\frac{1}{2}\left(s_{1}-s_{2}\right)
$$

and

$$
x_{2}=\frac{1}{2} X+\frac{1}{2}\left(s_{2}-s_{1}\right)
$$

It becomes obvious that the division of the marital output will not be equal unless the two threat points are the same. Hence, the threat points do not only represent the outcome in case of disagreement but also determine the internal sharing rule. Ceteris paribus within the Nash-bargaining frame-

\footnotetext{
${ }^{2}$ Other authors, e.g. Lundberg and Pollak (1993) as well as Konrad and Lommerud (1995), favor non-cooperative behavior within the household as the relevant threat point.

${ }^{3}$ Manser and Brown (1980) additionally include the partner's personal characteristics to the factors that determine the systematic utility of each individual. According to them, personal attributes of the partner like education and religion may also affect the utility out of consumption.
} 
work, the advantage of being married compared to being single is:

$$
x_{1}-s_{1}=\frac{1}{2} X-\frac{1}{2}\left(s_{1}+s_{2}\right)
$$

and

$$
x_{2}-s_{2}=\frac{1}{2} X-\frac{1}{2}\left(s_{1}+s_{2}\right) .
$$

The surprising result is that in case of Nash bargaining, irrespective of the threat points, the incentive to remain married is the same for both partners. Thus, the bargaining mechanism leads to an equalization of the difference between the share of output within the marriage and the spouse's outside option. This result, however, depends on the assumed symmetric bargaining power. Introducing asymmetric bargaining power by parameter $\beta$ modifies the optimization problem to:

$$
\max _{x_{1}, x_{2}}\left(x_{1}-s_{1}\right)^{\beta}\left(x_{2}-s_{2}\right)^{1-\beta}
$$

subject to

$$
x_{1}+x_{2}=X .
$$

The solutions are then:

$$
x_{1}-s_{1}=\beta X-\beta\left(s_{1}+s_{2}\right)
$$

and

$$
x_{2}-s_{2}=(1-\beta) X-(1-\beta)\left(s_{1}+s_{2}\right) .
$$

The difference between the monetary values of the marriage and the outside options is no longer the same. It is determined by the relative bargaining power within marriage. Moreover, it serves as a weighting factor of the threat points.

Similarly to the unitary model, the effect of education is not clear in this framework. Higher education improves labor market opportunities which in turn raises the threat point as well as the bargaining power. From this point of view, education and marital stability are negatively related. On 
the other hand, better labor market opportunities of both spouses may lead to a higher family income and thus, to a higher systematic utility out of consumption for both. As already discussed in section 2.1, the aspect of preferences concerning the educational level of the spouse (as modeled in Manser and Brown (1980)) is ambiguous.

The threat point is also determined by the probability of finding a more suitable partner than the current one. It can be reasoned that living in the city raises the probability of finding a better match which in turn increases the probability of marital disruption. Similarly, a working spouse might not only have a higher risk of divorce due to his or her financial independence but also because of a higher probability to meet a more suitable partner. Our previous discussion on the effects of religiousness applies to the bargaining model as well.

\section{Literature review}

Due to the steady increase of divorce rates in the last 50 years, the literature on divorce is quite extensive. Studies coming from different fields like economics, sociology, psychology, or genetics have analyzed various factors that may influence this trend and looked for the consequences for the persons involved. Our analysis is related to the literature about marital sorting and its impact on divorce which is far from being extensive in economics. More empirical studies of this topic can be found in the sociological literature. In the following, we consider both economic and sociological empirical analyses looking for the impact of religious and educational homogamy. The results are quite mixed.

As shown in section 2.1, Becker et al. (1977) derived numerous hypotheses concerning the effect of various spousal characteristics on risk of divorce. However, they were not able to test all of them because of data restrictions. With respect to own education, they do not find any statistically significant effect for the US which confirms their predicted ambiguity. In contrast, marrying outside own religion increases the probability of dissolution significantly. Weiss and Willis (1997) distinguish between the effects of an initially bad match and surprises while being married using data from the National 
Longitudinal Survey of High School Class 1972. In their analysis, homogamy with respect to religion as well as education stabilizes a marriage. In addition, they observe a lower divorce probability the higher the education of at least one spouse. In contrast, Charles and Stephens (2004) conclude that "the effect of education on marriage stability is less a matter of the similarity in schooling between husbands and wives as whether the couple is highly educated or not and whether it is the husband or wife with higher level of schooling." Namely, the reduction in divorce probability compared to the reference group is even higher for couples with a higher-educated husband than for couples with a higher-educated wife. Koch (1993) looks for these patterns using data from the first five SOEP-waves from 1984 to 1988. She analyzes divorce probabilities for marriages already existing in 1984. Her results indicate that couples that live in a predominantly Catholic federal state have a lower risk of divorce. In contrast, the difference in education does not affect marital stability. However, her education variable refers only to schooling neglecting the important aspect of vocational or university degree. Moreover, couples are not observed from the beginning of their marriage on so that the sample may consist of relatively stable couples having already mastered their first years of marriage.

Among sociologists the relationship between homogamy and divorce has been discussed more intensively. Usually, they also refer to the economic household models by Gary Becker. Again, the results are not clear. Bumpass and Sweet (1972), one of the earliest studies, and Bumpass et al. (1991) use the 1970 National Fertility Study and the National Survey of Families and Households (1987-1988) for the US, respectively. They find an inverse relationship between wife's educational attainment and the probability of divorce. However, their findings do not generally support the hypothesis that educational heterogamy is associated with a higher divorce risk. Instead, results of Bumpass et al. (1991) suggest that couples with a better educated wife have the highest risk of dissolution, followed by couples of the same education, whereas couples with a higher-educated husband have the lowest divorce probability. In contrast, Tzeng and Mare (1995), using US data from the National Longitudinal Surveys of Youth, of Young Men, and of Young Women, show that more education reduces the probability of dissolution, whereas heterogamy does not affect it. Finnäs (1997) find this 
pattern with Finnish data, too. In contrast to Charles and Stephens (2004), they do not observe a difference whether the husband or the wife is higher educated. These mixed results are also reflected in an international comparison of nine countries initiated by Blossfeld and Müller (2002). The analysis for West Germany (Müller (2003)) shows a (weakly) significant higher probability of divorce if the husband is higher educated than the wife compared to educationally homogamous couples. Previous research has, however, arrived at different conclusions with German data. Hall (1997) does not find a statistically significant impact of educational homogamy (schooling degree) on risk of divorce, whereas Kopp (2000) shows that homogamy with respect to schooling degree increases marital stability but with respect to vocational and university degree it has no effect. Both use data from the Mannheim divorce study but different samples. Wagner (1997) presents an elaborated analysis of determinants of divorce in West and East Germany with data from the German Life History Study. For West Germany, he shows a positive relationship between individual schooling and risk of divorce, in particular for women. More segmented analyses reveal that very low and very high educated persons have a higher risk of divorce. With respect to educational homogamy, there is no general evidence for a stabilizing impact even though he additionally distinguishes between the levels of education. However, his results are based only on a sample of couples from birth cohorts 1919-1921.

The impact of religion seems to be clearer. A stabilizing effect of religious homogamy and a destabilizing impact of religious heterogamy, respectively, can be found in Charles and Stephens (2004), Bumpass et al. (1991), and Bumpass and Sweet (1972) for the US and for Germany in Hall (1997). In the latter case, the variable refers to church attendance per month similar to our definition. Wagner (1997) and Diekmann and Klein (1991) find that people without denomination have a higher divorce probability than people with denomination. Müller (2003) finds the opposite. However, they all do not look for the impact of religious homogamy. 


\section{Empirical approach}

\subsection{Complementary log-log model}

Focus of our analysis is on the impact of certain explanatory variables on the conditional probability of getting divorced, i.e. the probability of getting divorced in time interval $t$ given that the couple has not separated until then. In most cases a proportional hazard model like the Cox model is used for this kind of questions. However, for our analysis with grouped duration data discrete-time models are better suited since they do not rely on the assumption that at most one transition per period occurs. Several authors have considered the discrete-time variant of the continuous proportional hazard model (e.g. Kiefer (1988), Meyer (1990)). However, we follow an alternative approach and use a binary choice model. Sueyoshi (1995) shows that the popular logit and probit models with period-specific dummy variables yield similar results to the discrete-time proportional hazard model. In fact, the complementary log-log model is perfectly equivalent to it (Cameron and Trivedi (2005)) and therefore, we use this model with marriage durationspecific dummy variables. The complementary log-log model is based on the type 1 extreme value distribution which is asymmetric in contrast to the logistic or standard normal distribution of the logit and probit model, respectively. This asymmetry makes cloglog models superior for the analysis of rare events like divorce.

Since the observations of one couple are likely correlated we use a robust variance estimator for the cloglog model that accounts for this correlation. In addition, we estimate a random effects cloglog model to consider the unobserved heterogeneity issue. There is an intensive discussion on the effect of unobserved heterogeneity on the estimation of duration models (see e.g. Cameron and Trivedi (2005)). It is shown that the coefficients of the covariates are affected by it, however, its identification is a non-trivial exercise. Nicoletti and Rondinelli (2006) discuss the random effects complementary log-log model that we use. They find that this model is robust to a possible misspecification of the distribution of the unobserved heterogeneity.

The integral of the random effect component in our model is approximated by using adaptive Gauss-Hermite quadrature with 20 quadrature points. 
Refitting the model with different numbers of quadrature points did not yield substantial changes in the results. ${ }^{4}$

\subsection{Sample}

Our data is taken from the West German sample of the SOEP, waves 1984 to $2007 .{ }^{5}$ The advantage of this data is the availability of a rather long time series of 24 periods and numerous control variables. It is possible to identify the time period when a marriage has begun and hence, we are able to account for the length of a marriage. Couples are observed until separation/divorce (whichever is stated first) or until observations are right-censored. In the following, we do not distinguish between separation and divorce and use them interchangeably.

We restrict our sample to couples where both spouses are in the age range from 18 to 65 at the time of marriage. Ultimately, the sample consists of 1,281 couples with 11,337 couple-years and 284 divorces and separations (see table 1). Hence, the observed probability of divorce is $2.51 \%$. 22.17 $\%$ of the couples finally separate. We pool first and later marriages: For 299 husbands (23.34 \%) and 306 wives (23.89\%), we observe a second or later marriage. In total, there are 454 couples $(35.4 \%)$ in which at least one spouse is not married for the first time.

Table 1: Transitions

\begin{tabular}{c|ccccc}
\hline \hline & \multicolumn{5}{|c}{ Destination } \\
Origin & Married & Separated & Divorced & Widowed & Total \\
\hline Married & 11,038 & 203 & 81 & 15 & 11,337 \\
\hline \hline
\end{tabular}

\footnotetext{
${ }^{4}$ For more details about the approximation method, see e.g. Liu and Pierce (1994) or in the context of random effects logit models, see Rabe-Hesketh and Skrondal (2008).

${ }^{5}$ The data used in this paper was extracted using the Add-On package PanelWhiz v2.0 Nov. 2007 for Stata. PanelWhiz (http://www.PanelWhiz.eu) was written by Dr. John P. Haisken-DeNew (john@PanelWhiz.eu). See Haisken-DeNew and Hahn (2006) for details. The PanelWhiz generated DO file to retrieve the data used here is available from us upon request. Any data or computational errors in this paper are our own.
} 
Figure 1 illustrates the Kaplan-Meier survivor function for the sample. It estimates the conditional probability of remaining married by period $t$ given that the couple has not separated until $t$. We see that the probability of remaining married decreases by 10 percentage points within the first 4 years of marriage. It further falls by 10 percentage points in the following 5 years. After a marriage duration of 10 years, the probability to stay together is ca. $76 \%$. After the maximum observation time of 22 years, the likelihood to stay married is still $63 \%$.

Figure 1: Kaplan-Meier survivor distribution function

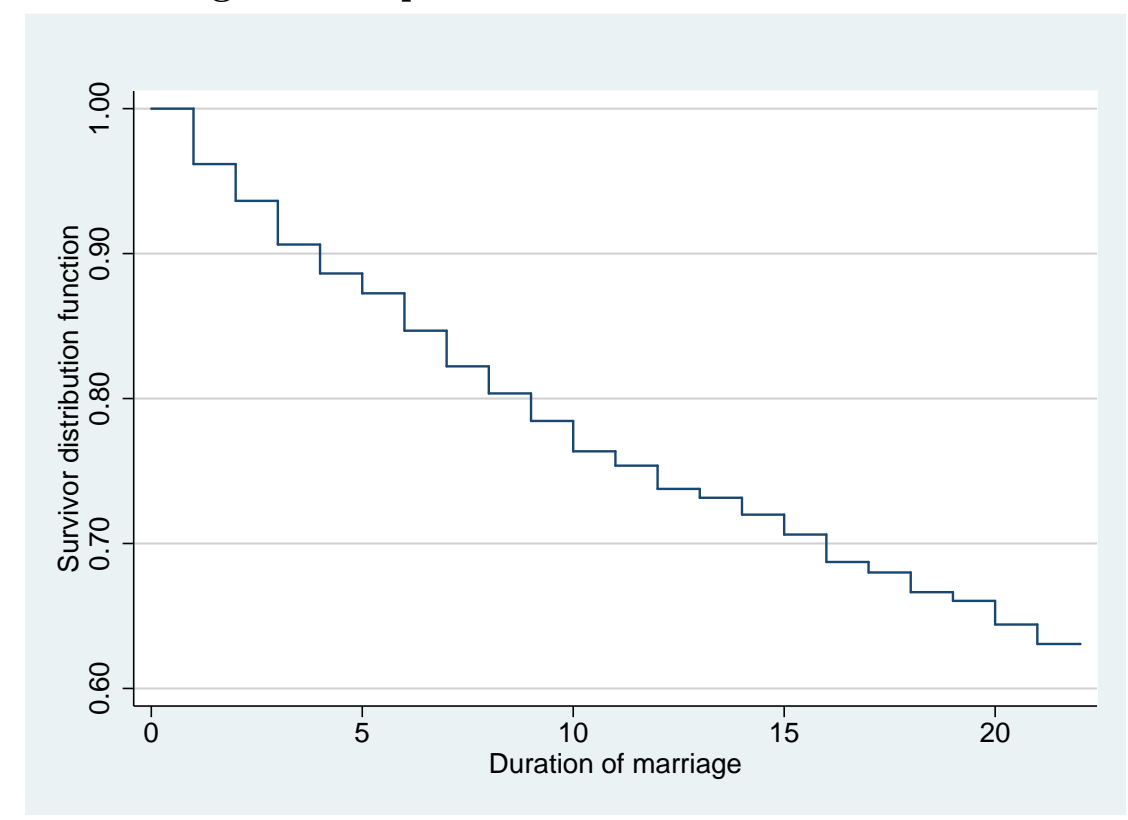

\section{Explanatory variables}

In the following, we explain the definition of our explanatory variables and present some descriptive statistics. Since the effects of education and religious affiliation are of main interest these variables are explained in more detail.

Following Blossfeld and Timm (2003), three hierarchical groups of education are classified: 
1. No schooling degree or Hauptschul- or Realschul-degree, without vocational degree ("Low");

2. No schooling degree or Hauptschul- or Realschul-degree, but with vocational degree or

Abitur/Fachhochschulreife, with or without vocational degree ("Medium");

3. University degree or degree of university of applied sciences ("High").

These three levels should reflect the main differences in labor market opportunities and earnings capacities as well as regarding their cultural resources (Blossfeld and Timm (2003)). Table 2 shows the distribution of educational levels at the beginning of the marriage for husbands and wives separately. The great majority of both sexes have medium education: $71 \%$ of hus-

Table 2: Distribution of educational level at the time of marriage

\begin{tabular}{|c|c|c|c|c|c|c|c|c|}
\hline \multirow{2}{*}{$\begin{array}{l}\text { Educ. } \\
\text { level }\end{array}$} & \multicolumn{4}{|c|}{ Husbands } & \multicolumn{4}{|c|}{ Wives } \\
\hline & No. & $\%$ & Obs. & $\%$ & No. & $\%$ & Obs. & $\%$ \\
\hline Low & 135 & 10.54 & 1,091 & 9.62 & 196 & 15.30 & 1,691 & 14.92 \\
\hline Med. & 913 & 71.27 & 8,239 & 72.67 & 939 & 73.30 & 8,532 & 75.26 \\
\hline High & 233 & 18.19 & 2,007 & 17.70 & 146 & 11.40 & 1,114 & 9.83 \\
\hline Total & 1,281 & 100.00 & 11,337 & 100.00 & 1,281 & 100.00 & 11,337 & 100.00 \\
\hline
\end{tabular}

bands and $73 \%$ of wives with around $73 \%$ and $75 \%$ of total observations, respectively. The percentage of husbands with a high educational level at the time of marriage is, however, much higher than of wives: $18 \%$ and 11 $\%$, respectively. A comparison with the distribution of educational levels in each period (see table 3) reveals slight shifts towards higher education. Hence, some persons in the sample attain a higher educational level during the observation period by finishing their vocational training or studies at university. For example, the percentage of high educated husbands rises to $22.1 \%$ and to $12.6 \%$ for wives. For the regressions, only the period-specific educational levels are used. Additional estimations using the educational 
levels at the time of marriage have shown, however, that results are not substantially altered.

Based on these three educational groups, we first defined nine possible

Table 3: Distribution of period-specific educational level

\begin{tabular}{l|rr|rr|rr|rr}
\hline \hline Educ. & \multicolumn{4}{|c|}{ Husbands } & \multicolumn{4}{c}{ Wives } \\
level & No. & $\%$ & Obs. & $\%$ & No. & $\%$ & Obs. & $\%$ \\
\hline Low & 126 & 9.84 & 1,010 & 8.90 & 184 & 14.36 & 1,623 & 14.32 \\
Med. & 872 & 68.07 & 8,048 & 70.99 & 936 & 73.07 & 8,488 & 74.87 \\
High & 283 & 22.09 & 2,279 & 20.10 & 161 & 12.57 & 1,226 & 10.81 \\
\hline Total & 1,281 & 100.00 & 11,337 & 100.00 & 1,281 & 100.00 & 11,337 & 100.00 \\
\hline \hline
\end{tabular}

Number of husbands and wives refer to stated education in their last sample year.

spousal combinations of education. Table 4 illustrates the distribution of period-specific educational combinations. It can be seen that educational homogamy is most common with a high proportion of two medium-educated partners $(54 \%)$. For less than $10 \%$ of the couples we observe a higher educated wife. Spouses with strongly divergent education are even less common: only 3 couples consist of a low-educated wife and a high-educated husband and vice versa. However, these small numbers make regression analysis problematic and therefore, we merged the high-educated spouse with their medium-educated peers, respectively. Alternatively, the low-educated partner could be combined with his or her medium-educated peers. However, given inherent labor market opportunities, equating medium- and higheducated people are, in our opinion, less questionable than merging lowand medium-educated individuals. Finally, we only distinguish between seven spousal combinations of education.

As indicator for religiousness, we use the question whether the individual attended church services or other religious events. In our opinion, this variable is superior to measure any religious association than religious denomination 
Table 4: Distribution of period-specific educational combinations

\begin{tabular}{l|rrr|r}
\hline \hline \multirow{2}{*}{$\begin{array}{l}\text { Husband's } \\
\text { education }\end{array}$} & \multicolumn{3}{|c|}{ Wife's education } & \\
\hline Low & 340 & 653 & 17 & 1,010 \\
& $(47)$ & $(76)$ & $(3)$ & $(126)$ \\
\multirow{4}{*}{ Medium } & 1,214 & 6,529 & 306 & 8,048 \\
& $(134)$ & $(694)$ & $(44)$ & $(872)$ \\
High & 69 & 1,307 & 903 & 2,279 \\
& $(3)$ & $(166)$ & $(114)$ & $(283)$ \\
\hline \multirow{2}{*}{ Total } & 1,623 & 8,488 & 1,226 & 11,337 \\
& $(184)$ & $(936)$ & $(161)$ & $(1,281)$ \\
\hline \hline
\end{tabular}

1) First row shows total number of observations.

2) Numbers in parentheses refer to the number of couples as stated in their last sample year.

in general. ${ }^{6}$ For our analysis, we generated a dummy variable "No church attendance" for each spouse that takes the value 1 if someone never attended church services and 0 if someone did so every week, every month or less frequently. We do not distinguish between different types of religion.

Table 5 shows the distribution of the variable for wives and husbands sep-

Table 5: Distribution of church attendance

\begin{tabular}{l|rr|r}
\hline \hline & Yes & No & Total \\
\hline Husband & 5,907 & 5,430 & 11,337 \\
& $(52.10)$ & $(47.90)$ & $(100.00)$ \\
Wife & 6,850 & 4,487 & 11,337 \\
& $(60.42)$ & $(39.58)$ & $(100.00)$ \\
\hline
\end{tabular}

Percentages in parentheses.

arately. We see that the majority state participation in religious activities, at least occasionally. It becomes also clear that wives are slightly more in-

\footnotetext{
${ }^{6}$ Both questions are not asked every year but for church attendance more frequently. For these years in which the question is not asked, preceding information is carried over.
} 
volved than husbands: $60 \%$ of wives compared to $52 \%$ of husbands went to church services or other religious events.

In order to estimate the impact of homogamy, four groups are defined:

1. Both spouses attended church services or other religious events,

2. both spouses did not attend,

3. only the wife attended, and

4. only the husband attended.

Table 6 illustrates the spousal combinations in our sample. We find a predominance of couples with two spouses who went to religious events. Couples with a participating husband and a non-participating wife are rather uncommon.

Table 6: Distribution of spousal combinations of church attendance

\begin{tabular}{l|rr|r}
\hline \hline \multirow{2}{*}{$\begin{array}{l}\text { Church } \\
\text { husband }\end{array}$} & \multicolumn{2}{|c|}{ Church wife } & \\
\hline \multirow{2}{*}{ Yes } & 5,081 & 826 & Notal \\
& $(44.82)$ & $(7.29)$ & $(52.10)$ \\
\multirow{2}{*}{ No } & 1,769 & 3,661 & 5,430 \\
& $(15.60)$ & $(32.29)$ & $(47.90)$ \\
\hline \multirow{2}{*}{ Total } & 6,850 & 4,487 & 11,337 \\
& $(60.42)$ & $(39.58)$ & $(100.00)$ \\
\hline \hline
\end{tabular}

Percentages in parentheses.

In addition to education and religion variables, we control for several other factors that potentially influence the risk of divorce. Some of them are correlated with our covariates of main interest.

Age at marriage is one of the most important explanatory variables in previous analyses of marital stability. Nevertheless, it is also correlated with 
education. Our data confirm that spouses with an academic degree tend to marry at a later age than others. Other factors related to both education and risk of divorce are income and unemployment. For our analysis, the former is specified as the household's total net income and the latter as the cumulated number of months in this state.

Another aspect of homogamy between two spouses is the age difference. We define it as the absolute difference between husband and wife, irrespective of who is the older one. Similar to educational or religious homogamy, being of a similar age should stabilize the relationship between two spouses. ${ }^{7}$ In order to test the hypothesis that urban life increases the risk of divorce because of the higher probability to meet a better match, we include a dummy variable for living in the city center. In contrast, children living in the household are expected to stabilize a marriage. We distinguish between children of different ages, namely age $0-1,2-7$, and $8-15$. However, we do not differentiate between own children, adoptive children and children from previous relationships. Additional controls are a dummy variable for a later marriage of at least one spouse, year of birth, and duration dummies.

All the variables mentioned so far are in each case measured in the period prior to the potential divorce. Thus, we estimate $\operatorname{Pr}\left(y_{i t} \neq 0 \mid \boldsymbol{x}_{i, t-1}\right)$. However, we deviate from this definition in the case of labor supply. Working behavior is an important potential risk factor of marital stability. It increases the financial independence as well as the opportunity to meet candidates for better suited matches. Moreover, it is correlated with education. In order to separate the direct influence of education on the risk of divorce and the indirect effect via labor supply, it is necessary to control for hours worked. Labor market behavior can, however, be largely influenced by the subjective probability of divorce (Johnson and Skinner (1986)). Therefore, we expect a change in hours worked in the preceding years to divorce, in particular by women, to become financially more independent. This would, however, bias our estimates. For that reason, we use the lagged variable hours worked of period $t-3$ instead of $t-1$ in order to circumvent this problem. ${ }^{8}$

\footnotetext{
${ }^{7}$ Various other specifications of the model that distinguish between an older husband and an older wife as well as between different degrees of the age difference neither provide evidence for a gender-specific difference nor for a non-linear impact.

${ }^{8}$ Results are, nevertheless, quite robust to the definition of hours worked. See appendix B for more details.
} 
Table 10 in appendix A summarizes descriptive statistics of the variables used in our regressions (except education and religion).

\section{Results}

Tables 7 and 8 present marginal effects instead of coefficients. In case of continuous variables, we show partial derivatives, whereas for dummy variables, the change in the predicted probability of divorce due to the discrete change from 0 to 1 is shown. Each derivative is evaluated at the means of the independent variables. ${ }^{9}$ The marginal effects are rather small which, however, can be attributed to the small probability of divorce. The predicted risk of separation is about $2 \%$ only. Standard errors are computed by the delta method.

Section 5.1 illustrates all estimation results if individual education and church attendance behavior are included. The impact of spousal combinations follow in section 5.2. Due to only small deviations, the presentation is in the latter case restricted to the impact of education and religion. For the random effects estimations (RE), tables include the likelihood-ratio (LR) test statistic for the hypothesis that the proportion of the total variance that is contributed by the panel-level variance, $\rho$, equals zero. If $\rho$ is zero the random effects estimator does not differ significantly from the pooled estimator. However, the hypothesis can be rejected on a $5 \%$ or $10 \%$ significance level, respectively.

\subsection{Effects of individual education and church attendance}

In our estimations, the dummy variable for a later marriage for at least one spouse does not show any significant effect on the probability of divorce. This result also holds for the year of birth-variables.

The impact of age at marriage is, however, not clear. Wife's age at marriage is in either case not significant. In contrast, husband's age has the expected negative effect on divorce probability but is not significant if a couple-specific random effect is controlled for. These results probably reflect our pooling

\footnotetext{
${ }^{9}$ See table 10 in appendix A.
} 
of first and later marriages. In contrast, age homogamy has the expected stabilizing effect in all regressions.

Children as marriage-specific investments are also supposed to stabilize a relationship. In our estimations, the effect depends on the age of children. We find a negative effect on the risk of divorce for newly born but not for children in general. The presence of children in the age range from 8 to 15 even raises the probability of separation. In contrast, as expected, city life lowers marital stability considerably even if we control for unobserved heterogeneity.

We have also expected religious persons to have a more stable relationship. In fact, we do find this pattern for religious husbands. Wife's behavior has, however, no effect in this respect.

The effect of education was a priori not clear. On the one hand, high education improves outside options. On the other hand, high-educated individuals are likely better able to form expectations and have therefore a lower risk to become disappointed. Our results suggest that the latter dominates. Medium- and high-educated people have a lower risk of divorce than loweducated ones. However, some effects are not significant. The weakness can in parts be attributed to the correlation with other explanatory variables like unemployment. Table 7 shows that if months of unemployment experience are included the effects of education become smaller and less significant. Moreover, the direct impact of unemployment is not gender-neutral. Husband's unemployment lowers marital stability as expected. However, if the wife loses her job the risk of divorce is not significantly altered. Thus, only husband's unemployment implies a substantial negative shock to gains from marriage in our estimations. Household's net income, another factor related to education, has no significant impact on the risk of divorce at all.

The effect of hours worked is also not gender-neutral. Husband's hours worked have a stabilizing effect, whereas wife's hours (weakly) destabilize a relationship in our random effects-estimations. 
Table 7: Marginal effects I

\begin{tabular}{|c|c|c|c|c|}
\hline & cloglog I & cloglog II & RE I & RE II \\
\hline Not first marriage (d) & -0.0008 & -0.0010 & -0.0010 & -0.0015 \\
\hline H: Age at marriage & $-0.0007 * *$ & $-0.0008^{* * *}$ & -0.0005 & -0.0005 \\
\hline W: Age at marriage & 0.0004 & 0.0004 & 0.0002 & 0.0003 \\
\hline Age difference & $0.0010^{* * *}$ & $0.0009^{* * *}$ & $0.0008^{* * *}$ & $0.0007^{* *}$ \\
\hline H: Year of birth & -0.0003 & -0.0003 & -0.0002 & -0.0002 \\
\hline W: Year of birth & 0.0005 & 0.0005 & 0.0003 & 0.0003 \\
\hline No. of HH members age $0-1$ & $-0.0119 * * *$ & $-0.0119^{* * *}$ & $-0.0107 * *$ & $-0.0101^{* *}$ \\
\hline No. of HH members age $2-7$ & 0.0006 & 0.0001 & 0.0003 & -0.0001 \\
\hline No. of HH members age 8-15 & $0.0065^{* * *}$ & $0.0062^{* * *}$ & $0.0057^{* * *}$ & $0.0051^{* * *}$ \\
\hline Live in City $(\mathrm{d})$ & $0.0123^{* *}$ & $0.0116^{* *}$ & $0.0110^{* *}$ & $0.0099^{* *}$ \\
\hline HH net income & 0.0012 & 0.0014 & 0.0011 & 0.0013 \\
\hline H: High-educated (d) & $-0.0108^{* * *}$ & $-0.0086^{* *}$ & $-0.0095^{* * *}$ & $-0.0072^{* *}$ \\
\hline H: Medium-educated (d) & $-0.0095^{* *}$ & -0.0065 & $-0.0085^{* *}$ & -0.0055 \\
\hline W: High-educated (d) & -0.0061 & -0.0054 & $-0.0066^{*}$ & $-0.0062^{*}$ \\
\hline W: Medium-educated (d) & $-0.0088^{* *}$ & $-0.0075^{*}$ & $-0.0091^{* *}$ & $-0.0079 * *$ \\
\hline H: No church att. (d) & $0.0118^{* * *}$ & $0.0109^{* * *}$ & $0.0098^{* * *}$ & $0.0086^{* * *}$ \\
\hline W: No church att. (d) & 0.0027 & 0.0028 & 0.0027 & 0.0026 \\
\hline H: Hours worked t-3 & $-0.0002^{* *}$ & $-0.0001^{*}$ & $-0.0002^{* *}$ & -0.0001 \\
\hline W: Hours worked t-3 & 0.0001 & 0.0001 & $0.0001^{*}$ & $0.0001^{*}$ \\
\hline H: No. months in UE cum. & & $0.0002^{* *}$ & & $0.0002^{* * *}$ \\
\hline W: No. months in UE cum. & & 0.0001 & & 0.0001 \\
\hline Rho & & & 0.28313 & 0.34589 \\
\hline p-value $H_{0}: R h o=0$ & & & 0.063 & 0.025 \\
\hline Chi2 & 150.38 & 173.31 & 118.35 & 119.82 \\
\hline
\end{tabular}

1) Table shows marginal effects computed at the mean of each covariate except for dummies.

(d) for discrete change of dummy variable from 0 to 1 .

2) *: $\mathrm{p}<0.10,{ }^{* *}: \mathrm{p}<0.05,{ }^{* * *} \mathrm{p}<0.01$; st.err. computed by the delta method.

3) "H:" stands for husbands, "W:" for wives, "HH" for household.

4) Reference group: low education

5) Effects for duration dummies not presented. 


\subsection{Effects of spousal combinations of education and church attendance}

Table 8 illustrates the influence of spousal combinations of education and church attendance. In general, we do not find evidence for a stabilizing impact of homogamy neither concerning education nor concerning religion.

Even though we observe the highest decrease in risk of dissolution for homogamous medium-educated mates, couples with two low-educated spouses have a significantly higher probability of divorce than any other combination. The smallest changes can be found for the combinations with one low-educated spouse. Hence, our results suggest that not the combination of education but low versus medium and high education matters. Spouses with a low educational level realize higher divorce risks than spouses with medium or high education. This supports our previous findings of the im-

Table 8: Marginal effects II (Extract)

\begin{tabular}{lcc}
\hline \hline & cloglog III & RE III \\
\hline $\mathrm{H}-\mathrm{H}(\mathrm{d})$ & $-0.0134^{* * *}$ & $-0.0122^{* * *}$ \\
$\mathrm{M}-\mathrm{M}(\mathrm{d})$ & $-0.0182^{* * *}$ & $-0.0177^{* * *}$ \\
$\mathrm{H} / \mathrm{M}-\mathrm{L}(\mathrm{d})$ & $-0.0096^{* *}$ & $-0.0083^{* * *}$ \\
$\mathrm{H}-\mathrm{M}(\mathrm{d})$ & $-0.0143^{* * *}$ & $-0.0125^{* * *}$ \\
$\mathrm{M}-\mathrm{H}(\mathrm{d})$ & $-0.0107^{* * *}$ & $-0.0100^{* * *}$ \\
$\mathrm{~L}-\mathrm{H} / \mathrm{M}(\mathrm{d})$ & $-0.0104^{* * *}$ & $-0.0095^{* * *}$ \\
Both no church att. (d) & $0.0161^{* * *}$ & $0.0134^{* * *}$ \\
Only H church (d) & $0.0133^{*}$ & $0.0107^{*}$ \\
Only W church (d) & $0.0187^{* * *}$ & $0.0150^{* * *}$ \\
\hline Rho & & 0.31818 \\
p-value $H_{0}:$ Rho $=0$ & & 0.037 \\
Chi2 & 188.75 & 124.79 \\
\hline \hline
\end{tabular}

1) First six rows refer to education. First letter stands for husband's, second for wife's. "H" denotes high education, "M" medium, and "L" low.

2) Reference groups: both low-educated; both go to church 
pact of individual education, however, the significance is now much higher. In contrast to Charles and Stephens (2004), we do not find evidence that it matters who is higher educated. Regressions with alternating reference groups neither yield significant differences between "H-M" and "M-H" nor between "H/M-L" and "L-H/M". ${ }^{10}$

Church attendance of both spouses has the expected stabilizing effect. Each of the three other combinations has a substantially higher probability of dissolution. However, couples with two non-attending spouses have not a significantly lower divorce risk than couples where only one spouse goes to religious events (see table 9 for results of random effects-estimations with different reference groups). Thus, as in the case of education, homogamy itself does not stabilize the relationship but religiousness versus non-religiousness. One possible explanation is the aspect of sharing leisure time together inherent in our variable "Both attended church service". This might reduce the probability of separation. Alternatively, religiousness itself matters because it implies a high valuation to be married by both spouses and not similarity in this attitude.

Even though the destabilizing effect is higher if only the wife attends church service than if only the husbands attends in regression RE-CH I, we do not find a significant difference between the two groups in the direct comparisons RE-CH III and RE-CH IV. Hence, as for education, we do not observe gender-specific differences.

Table 9: Effect of reference group church attendance (Extract)

\begin{tabular}{lllll}
\hline \hline & RE-CH I & RE-CH II & RE-CH III & RE-CH IV \\
\hline Both no church att. (d) & $0.0134^{* * *}$ & & 0.0032 & 0.0001 \\
Both church att. (d) & & $-0.0113^{* * *}$ & $-0.0083^{* *}$ & $-0.0112^{* * *}$ \\
Only H church (d) & $0.0107^{*}$ & -0.0028 & & -0.0028 \\
Only W church (d) & $0.0150^{* * *}$ & -0.0001 & 0.0032 & \\
\hline \hline
\end{tabular}

\footnotetext{
${ }^{10}$ Results are not presented.
} 


\section{Conclusions}

Using a rich panel data set on German couples, we test the hypothesis that homogamy increases marital stability. Becker assumes that earnings capacities should be dissimilar but traits like intelligence, age, religion, and education should be positively correlated.

We put an emphasis on education and religiousness measured by attendance of church services and other religious events. Education is affected by intelligence and preferences concerning the division of labor within the marriage. On the other hand, income prospects also depend on education. Hence, educational attainment may affect the stability of a relationship in multiple ways. Religious affiliation expresses views concerning the importance of marriage. As we have information for both spouses on that we can test for the effects of similarity and dissimilarity of preferences.

Our cloglog estimations, considering also couple-specific unobserved heterogeneity, do not generally show that two spouses who are similar to each other have a lower risk of divorce than dissimilar spouses. A stabilizing effect of homogamy can be found for age: the risk of divorce increases with increasing age difference. In contrast, a stabilizing effect with respect to education and church attendance can only be found for certain groups like couples with two medium- or two high-educated spouses, or if both attend religious events. Our results suggest that not the combination matters but low versus medium or high level education and church attendance of both spouses versus no church attendance of at least one spouse. Spouses with a low educational level and couples without religious affiliation realize significantly higher divorce risks. Therefore, other aspects of these characteristics and activities seem to play an important role. Examples are sharing leisure time together or the ability to form expectations.

So far, we have neglected important financial aspects in addition to household's total net income. It is, nevertheless, very likely that not only hours worked but the associated individual wage as well as non-labor income and property influence the success of a relationship. 


\section{A Descriptive statistics}

Table 10: Descriptive statistics of explanatory variables

\begin{tabular}{l|rr}
\hline \hline Variable & Mean & Std. Dev. \\
\hline For at least one spouse not first marriage & 0.35 & 0.48 \\
H: Age at marriage & 32.19 & 8.28 \\
W: Age at marriage & 29.43 & 7.43 \\
Absolute age difference & 4.06 & 3.98 \\
H: Year of birth & 1960 & 9.05 \\
W: Year of birth & 1962 & 8.17 \\
Live in city center & 0.09 & 0.28 \\
No. of HH members age 0-1 & 0.14 & 0.36 \\
No. of HH members age 2-7 & 0.57 & 0.75 \\
No. of HH members age 8-15 & 0.39 & 0.71 \\
Household's net income in 1,000 Euro of 2002 & 2.64 & 1.30 \\
H: Cum. number of months in UE & 5.41 & 14.52 \\
W: Cum. number of months in UE & 5.41 & 10.75 \\
H: Hours worked (per week) in t-3 & 40.13 & 14.19 \\
W: Hours worked (per week) in t-3 & 19.41 & 17.51 \\
\hline \hline
\end{tabular}

1)"H:" stands for husbands, "W:" for wives, "HH" for household, "UE" for unemployment.

2) All variables refer to period t-1 except hours worked.

\section{B Definition of hours worked}

Figures 2 and 3 show the development of average hours worked in the years preceding divorce. The figures for divorced wives and divorced husbands refer to the average hours worked of those couples that eventually divorce, but while they are still married. Only the short-dashed lines give the mean of all female and male observations, respectively. It becomes obvious that wives and husbands that eventually divorce work generally more on average than the pool of all wives and husbands. However, the difference is almost negligible for husbands. For both sexes, we observe a change in working behavior prior to divorce. Husbands work less while wives widen their labor 
supply. In either case, the period-specific mean crosses the average of the divorced between $t-4$ and $t-3$. Therefore, we use data of $t-3$ for our regressions to diminish the endogeneity problem.

Nevertheless, we tested the effect of the definition of hours worked on our variables of interest. Tables 11 and 12 compare the marginal effects of random effects estimations if hours worked of different periods from $t-1$ to $t-5$ are used. We can see that the results are only slightly affected by the definition of hours worked. Not surprisingly, the biggest changes can be observed in the effects of children. The impact of new-born children in $t-1$ is insignificant if hours worked of period $t-1$ is included. With labor supply of later periods, the effect becomes larger and significant. Apparently, this children-variable captures partly the effect of a non-working wife in period $t-1$.

Figure 2: Means of husbands' hours worked in years prior to divorce

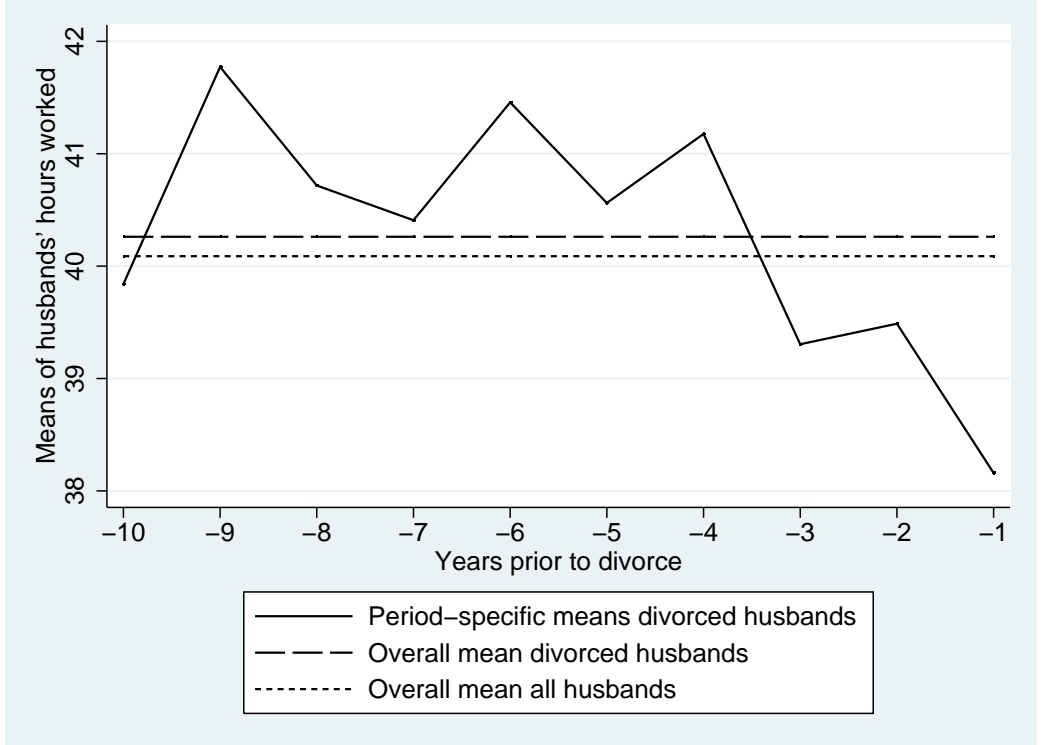


Figure 3: Means of wives' hours worked in years prior to divorce

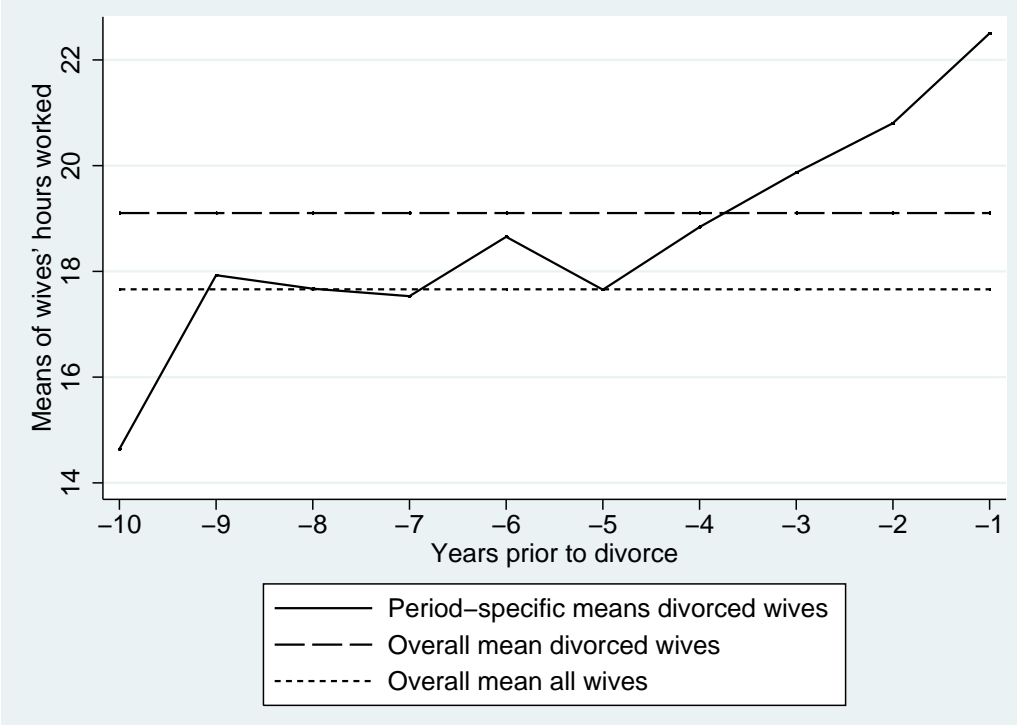


Table 11: Effect period hours worked on RE estimations I

\begin{tabular}{|c|c|c|c|c|c|}
\hline & H Ia & H IIa & H IIIa & H IVa & $\mathrm{H} \mathrm{Va}$ \\
\hline Not first marriage & -0.0015 & -0.0015 & -0.0015 & -0.0014 & -0.0013 \\
\hline H: Age at marriage & -0.0004 & -0.0004 & -0.0005 & -0.0005 & -0.0005 \\
\hline W: Age at marriage & 0.0002 & 0.0003 & 0.0003 & 0.0002 & 0.0002 \\
\hline Age difference & $0.0007^{* *}$ & $0.0007^{* *}$ & $0.0007^{* *}$ & $0.0007^{* *}$ & $0.0007^{* *}$ \\
\hline H: Year of birth & -0.0001 & -0.0001 & -0.0002 & -0.0002 & -0.0001 \\
\hline W: Year of birth & 0.0003 & 0.0003 & 0.0003 & 0.0003 & 0.0002 \\
\hline No. of HH mem. $0-1$ & -0.0060 & $-0.0089^{* *}$ & $-0.0101^{* *}$ & $-0.0101^{* *}$ & $-0.0102^{* *}$ \\
\hline No. of $\mathrm{HH}$ mem. $2-7$ & 0.0006 & 0.0005 & -0.0001 & -0.0010 & -0.0015 \\
\hline No. of HH mem. 8-15 & $0.0051^{* * *}$ & $0.0049^{* * *}$ & $0.0051^{* * *}$ & $0.0047^{* *}$ & $0.0043^{* *}$ \\
\hline Live in City & $0.0095^{* *}$ & $0.0096^{* *}$ & $0.0099^{* *}$ & $0.0102^{* *}$ & $0.0102^{* *}$ \\
\hline HH net income & 0.0009 & 0.0008 & 0.0013 & 0.0012 & 0.0012 \\
\hline H: High-educated & $-0.0064^{*}$ & $-0.0069^{* *}$ & $-0.0072^{* *}$ & $-0.0073^{* *}$ & $-0.0071^{* *}$ \\
\hline H: Medium-educated & -0.0050 & -0.0055 & -0.0055 & -0.0054 & -0.0052 \\
\hline W: High-educated & $-0.0068^{* *}$ & $-0.0064^{* *}$ & $-0.0062^{*}$ & $-0.0060^{*}$ & $-0.0060^{*}$ \\
\hline W: Medium-educated & $-0.0080^{* *}$ & $-0.0078^{* *}$ & $-0.0079^{* *}$ & $-0.0076^{* *}$ & $-0.0075^{* *}$ \\
\hline H: No church att. & $0.0082^{* * *}$ & $0.0082^{* * *}$ & $0.0086^{* * *}$ & $0.0087^{* * *}$ & $0.0088^{* * *}$ \\
\hline W: No church att. & 0.0027 & 0.0025 & 0.0026 & 0.0027 & 0.0027 \\
\hline H: No. mon. UE cum. & $0.0002^{* * *}$ & $0.0002^{* * *}$ & $0.0002^{* * *}$ & $0.0002^{* * *}$ & $0.0002^{* * *}$ \\
\hline W: No. mon. UE cum. & 0.0001 & 0.0001 & 0.0001 & 0.0001 & 0.0001 \\
\hline H: Hours work t-1 & -0.0001 & & & & \\
\hline W: Hours work t-1 & $0.0002^{* * *}$ & & & & \\
\hline H: Hours work t-2 & & 0.0001 & & & \\
\hline W: Hours work t-2 & & $0.0002^{* *}$ & & & \\
\hline H: Hours work t-3 & & & -0.0001 & & \\
\hline W: Hours work t-3 & & & $0.0001^{*}$ & & \\
\hline H: Hours work t-4 & & & & 0.0001 & \\
\hline W: Hours work t-4 & & & & 0.0001 & \\
\hline H: Hours work t-5 & & & & & 0.0001 \\
\hline W: Hours work t-5 & & & & & -0.0001 \\
\hline Rho & 0.36503 & 0.38060 & 0.34589 & 0.35017 & 0.34674 \\
\hline p-value $H_{0}: R h o=0$ & 0.019 & 0.015 & 0.025 & 0.026 & 0.028 \\
\hline Chi2 & 120.76 & 115.74 & 119.82 & 113.83 & 114.43 \\
\hline
\end{tabular}

1) Table shows marginal effects computed at the mean of each covariate except for dummies.

2) *: $\mathrm{p}<0.10,{ }^{*}: \mathrm{p}<0.05,{ }^{* * *} \mathrm{p}<0.01$; st.err. computed by the delta method.

3) "H:" stands for husbands, "W:" for wives, "HH" for household. 
Table 12: Effect period hours worked on RE estimations II (Extract)

\begin{tabular}{|c|c|c|c|c|c|}
\hline & $\mathrm{H} \mathrm{Ib}$ & $\mathrm{H} \mathrm{IIb}$ & H IIIb & $\mathrm{H} \mathrm{IVb}$ & $\mathrm{H} \mathrm{Vb}$ \\
\hline $\mathrm{H}-\mathrm{H}$ & $-0.0119 * * *$ & $-0.0119^{* * *}$ & $-0.0122^{* * *}$ & $-0.0119^{* * *}$ & $-0.0117^{* * *}$ \\
\hline $\mathrm{M}-\mathrm{M}$ & $-0.0172^{* * *}$ & $-0.0175^{* * *}$ & $-0.0177^{* * *}$ & $-0.0168^{* * *}$ & $-0.0162^{* * *}$ \\
\hline $\mathrm{H} / \mathrm{M}-\mathrm{L}$ & $-0.0079 * *$ & $-0.0080^{* *}$ & $-0.0083^{* * *}$ & $-0.0079 * *$ & $-0.0076^{* *}$ \\
\hline $\mathrm{H}-\mathrm{M}$ & $-0.0120 * * *$ & $-0.0121^{* * *}$ & $-0.0125^{* * *}$ & $-0.0123^{* * *}$ & $-0.0121^{* * *}$ \\
\hline $\mathrm{M}-\mathrm{H}$ & $-0.0101^{* * *}$ & $-0.0099 * * *$ & $-0.0100^{* * *}$ & $-0.0098^{* * *}$ & $-0.0097 * * *$ \\
\hline $\mathrm{L}-\mathrm{H} / \mathrm{M}$ & $-0.0094^{* * *}$ & $-0.0092^{* * *}$ & $-0.0095^{* * *}$ & $-0.0090 * * *$ & $-0.0088^{* * *}$ \\
\hline Both no church att. & $0.0131^{* * *}$ & $0.0129^{* * *}$ & $0.0134^{* * *}$ & $0.0136^{* * *}$ & $0.0137^{* * *}$ \\
\hline Only H church & $0.0110^{*}$ & $0.0104^{*}$ & $0.0107^{*}$ & $0.0111^{*}$ & $0.0112^{*}$ \\
\hline Only W church & $0.0145^{* * *}$ & $0.0145^{* * *}$ & $0.0150^{* * *}$ & $0.0153^{* * *}$ & $0.0154^{* * *}$ \\
\hline H: Hours work t-1 & -0.0001 & & & & \\
\hline W: Hours work t-1 & $0.0002^{* * *}$ & & & & \\
\hline H: Hours work t-2 & & 0.0001 & & & \\
\hline W: Hours work t-2 & & $0.0002^{* *}$ & & & \\
\hline H: Hours work t-3 & & & $-0.0001^{*}$ & & \\
\hline W: Hours work t-3 & & & $0.0001^{*}$ & & \\
\hline H: Hours work t-4 & & & & 0.0001 & \\
\hline W: Hours work t-4 & & & & 0.0001 & \\
\hline H: Hours work t-5 & & & & & 0.0001 \\
\hline W: Hours work t-5 & & & & & -0.0001 \\
\hline Rho & 0.33659 & 0.35570 & 0.31812 & 0.32711 & 0.32493 \\
\hline $\mathrm{p}$-value $H_{0}: R h o=0$ & 0.029 & 0.022 & 0.037 & 0.036 & 0.038 \\
\hline Chi2 & 125.74 & 120.19 & 124.79 & 117.89 & 118.26 \\
\hline
\end{tabular}

1) Table shows marginal effects computed at the mean of each covariate except for dummies.

2) *: $\mathrm{p}<0.10,{ }^{* *}: \mathrm{p}<0.05,{ }^{* * *} \mathrm{p}<0.01$; st.err. computed by the delta method.

3) "H:" stands for husbands, "W:" for wives.

4) First six rows refer to education. First letter stands for husband's, second for wife's. "H" denotes high education, "M" medium, and "L" low. 


\section{References}

Becker, G. S. (1973). A theory of marriage: Part I. Journal of Political Economy, 81(4):813-846.

Becker, G. S. (1974a). A theory of marriage: Part II. Journal of Political Economy, 82(2):S11-S26.

Becker, G. S. (1974b). A theory of social interactions. Journal of Political Economy, 82(6):1063-1093.

Becker, G. S. (1981). A Treatise on the Family. Harvard University Press.

Becker, G. S., Landes, E. M., and Michael, R. T. (1977). An economic analysis of marital instability. Journal of Political Economy, 85(6):11411187.

Binmore, K., Rubinstein, A., and Wolinsky, A. (1986). The Nash bargaining solution in economic modelling. Rand Journal of Economics, 17(2):176188.

Blossfeld, H.-P. and Müller, R. (2002). Union disruption in comparative perspective: The role of assortative partner choice and careers of couples. International Journal of Sociology, 32(4):3-35. Guest Editor's Introduction.

Blossfeld, H.-P. and Timm, A. (2003). Who marries whom in West Germany? In Blossfeld, H.-P. and Timm, A., editors, Who marries whom? Educational systems as marriage markets in modern societies, pages 1935. Kluwer Academic Publishers.

Browning, M., Bourguignon, F., Chiappori, P.-A., and Lechene, V. (1994). Income and outcomes: A structural model of intrahousehold allocation. Journal of Political Economy, 102(6):1067-1096.

Bumpass, L. L., Martin, T. C., and Sweet, J. A. (1991). The impact of family background and early marital factors on marital disruption. Journal of Family Issues, 12(1):22-42.

Bumpass, L. L. and Sweet, J. A. (1972). Differentials in marital stability: 1970. American Sociological Review, 37(6):754-766. 
Cameron, A. C. and Trivedi, P. K. (2005). Microeconometrics. Methods and applications. Cambridge University Press.

Charles, K. K. and Stephens, M. (2004). Job displacement, disability, and divorce. Journal of Labor Economics, 22(2):489-522.

Diekmann, A. and Klein, T. (1991). Bestimmungsgründe des Ehescheidungsrisikos. Eine empirische Untersuchung mit den Daten des sozioökonomischen Panels. Kölner Zeitschrift für Soziologie und Sozialpsychologie, 43(2):271-290.

Finnäs, F. (1997). Social integration, heterogeneity, and divorce: The case of the swedish-speaking population in finland. Acta Sociologica, 40(3):263277.

Haisken-DeNew, J. P. and Hahn, M. (2006). Panelwhiz: A flexible modularized stata interface for accessing large scale panel data sets. (http://www.PanelWhiz.eu). mimeo.

Hall, A. (1997). Drum prüfe, wer sich ewig bindet. Eine empirische Untersuchung zum Einfluss vorehelichen Zusammenlebens auf das Scheidungsrisiko. Zeitschrift für Soziologie, 26(4):275-295.

Hoddinott, J. and Haddad, L. (1995). Does female income share influence household expenditure? Evidence from Cote d'Ivoire. Oxford Bulletin of Economics and Statistics, 57(1):77-96.

Johnson, W. R. and Skinner, J. (1986). Labor supply and marital separation. American Economic Review, 76(3):455-469.

Kiefer, N. M. (1988). Economic duration data and hazard functions. Journal of Economic Literature, 26(2):646-679.

Koch, A. (1993). An economic analysis of marital dissolution in West Germany. Münchener wirtschaftswissenschaftliche Beiträge, 93-10.

Konrad, K. A. and Lommerud, K. E. (1995). Family policy with noncooperative families. Scandinavian Journal of Economics, 97(4):581-601.

Kopp, J. (2000). Socio-structural determinants of divorce: A test of some hypotheses of the economic theory of the family. In Weesie, J. and Raub, 
W., editors, The Management of durable relations: Theoretical models and empirical studies of households and organizations. ThelaThesis.

Lewis, S. K. and Oppenheimer, V. K. (2000). Educational assortative mating across marriage markets: Non-hispanic whites in the united states. Demography, 37(1):29-40.

Liu, Q. and Pierce, D. A. (1994). A note on Gauss-Hermite quadrature. Biometrika, 81(3):624-629.

Lundberg, S. and Pollak, R. A. (1993). Separate spheres bargaining and the marriage market. Journal of Political Economy, 101(6):988-1010.

Manser, M. and Brown, M. (1980). Marriage and household decision-making: A bargaining analysis. International Economic Review, 21(1):31-44.

McElroy, M. B. and Horney, M. J. (1981). Nash-bargained household decisions: Toward a generalization of the theory of demand. International Economic Review, 22(2):333-349.

Meyer, B. D. (1990). Unemployment insurance and unemployment spells. Econometrica, 58(4):757-782.

Müller, R. (2003). Union disruption in West Germany. Educational homogeneity, children, and trajectories in marital and nonmarital unions. International Journal of Sociology, 33(2):3-35.

Nash, J. F. (1950). The bargaining problem. Econometrica, 18(2):155-162.

Nicoletti, C. and Rondinelli, C. (2006). The (mis)specification of discrete time duration models with unobserved heterogeneity: a monte carlo study. ISER Working Paper 2006-53.

Nielsen, H. S. and Svarer, M. (2006). Educational homogamy: Preferences or opportunities? IZA Discussion Paper No. 2271.

Rabe-Hesketh, S. and Skrondal, A. (2008). Multilevel and longitudinal modeling using Stata. Stata Press, 2nd edition.

Statistisches Bundesamt (2005). Ehescheidungen 2004. Wirtschaft und Statistik, 12:1273-1282. 
Sueyoshi, G. T. (1995). A class of binary response models for grouped duration data. Journal of Applied Econometrics, 10(4):411-431.

Tzeng, J. M. and Mare, R. D. (1995). Labor market and socioeconomic effects on marital stability. Social Science Research, 24(4):329-351.

Wagner, M. (1997). Scheidung in Ost- und Westdeutschland. Zum Verhältnis von Ehestabilität und Sozialstruktur seit den 30er Jahren. Campus Verlag.

Weiss, Y. and Willis, R. J. (1997). Match quality, new information, and marital dissolution. Journal of Labor Economics, 15(1, part 2):S293-S329. 